\title{
GESTÃO E CONFLITOS EM UNIDADES DE CONSERVAÇÃO: GESTÃO ESTRATÉGICA E OPERACIONAL PARA PRESERVAÇÃO AMBIENTAL ${ }^{1}$
}

\author{
Shana Sabbado Flores ${ }^{2}$ \\ Prof. Dr. Nelson Sambaqui Gruber ${ }^{3}$ \\ Profa. Dr. Rosa Maria Vieira Medeiros ${ }^{4}$
}

\section{Resumo}

Os conceitos de sustentabilidade e gestão da zona costeira exigem reflexão sobre uma série de aspectos socioeconômicos e ambientais. Esses ambientes estão sobre constante pressão, contexto que gera conflitos e antagonismos exigindo gerenciamento integrado para efetivação de um plano de desenvolvimento mais sustentável. Para tanto, uma estratégia adotada é a delimitação de áreas protegidas, cujo conceito é antigo (ex. na Pérsia e Mesopotâmia). Essas áreas nasceram para preservação da natureza em sentido amplo, abrangendo hoje temas diversos e estabelece limites e dinâmicas de uso e ocupação, podendo ser considerada como uma estratégia de planejamento e controle do território. $\mathrm{O}$ trabalho tem como foco a discussão sobre a gestão em áreas de preservação, utilizando como exemplos práticos as UCs do Parque Nacional da Lagoa do Peixe (Tavares-Mostardas) e do Parque Natural Municipal Tupancy (Arroio do Sal), ambas no litoral do RS. O conceito de gestão é encarado de forma ampla, envolvendo arcabouço legal e conceitual brasileiro, ferramentas de gestão e integração, a gestão das unidades em si e os conflitos decorrentes do processo - principalmente relacionados à agropecuária, pescadores, pressão imobiliária, atividade turística, além de legislação e competências.

\footnotetext{
${ }^{1}$ Trabalho desenvolvido ao longo da disciplina de Gestão e Gerenciamento da Zona Costeira (GPG00022), Programa de Pós-Graduação em Geografia, Instituto de Geociências, Universidade Federal do Rio Grande do Sul, no 1 o semestre de 2009.

${ }^{2}$ Mestranda em Geografia no Programa de Pós-Graduação em Geografia, Instituto de Geociências, Universidade Federal do Rio Grande do Sul. Administradora de empresas. E-mail: shanasabbado@yahoo.com.br

${ }^{3}$ Prof. Dr. no Programa de Pós-Graduação em Geografia, Instituto de Geociências, Universidade Federal do Rio Grande do Sul. E-mail: nelson.gruber@ufrgs.br

${ }^{4}$ Profa. Dra. no Programa de Pós-Graduação em Geografia, Instituto de Geociências, Universidade Federal do Rio Grande do Sul. E-mail: rmvmedeiros@yahoo.com.br
} 
Palavras-chave: unidades de conservação, áreas de preservação, gestão da zona costeira, gestão ambiental, sustentabilidade.

\begin{abstract}
The concepts of sustainability and coastal zone management requires the consideration of a great range of socioeconomic and environmental aspects. These environments are under constant pressure, a context that generates conflicts and antagonisms, that requires integrated management to effect a plan for more sustainable development. Therefore, an adopted strategy is the protected areas demarcation, wich concept is quite old (eg in Persia and Mesopotamia). These areas were established to conserve nature in the broadest sense, with teritorial limits demarcation, and its dynamics of use and occupation, that can be considered as a strategy for territory planning and control. The focus of this paper is the discussion about the management of protected areas, using as pratical examples the areas of the Lagoa do Peixe National Park (Tavares-Mostardas) and the Tupancy Municipal Natural Park (Arroio do Sal), both on the coast of RS. The concept of management is broadly explored, involving Brazilian legal and conceptual framework, management and integration tools, the protected areas management, and the conflicts involved in this process - mainly related to agriculture, fishing, residential estate expansion, tourism, legislation and political responsibilities.
\end{abstract}

Key words: conservation areas, coastal zone management, environmental management, sustainability

\title{
1. Zona Costeira e Preservação Ambiental
}

Em uma visão ampla do conceito de gestão e gerenciamento da zona costeira, somos obrigados a refletir sobre uma série de diversos aspectos socioeconômicos e ambientais, tais como ocupação territorial, preservação de ecossistemas, exploração mineral, recursos pesqueiros e desenvolvimento econômico entre outros inúmeros fatores.

A reflexão sobre tais pontos torna-se cada vez mais estratégica na medida em que a tendência para o próximo século é que $80 \%$ das atividades humanas estejam concentradas nos ambientes litorâneos. No atual contexto, a ocupação territorial no Brasil e em muitos outros países está concentrada no litoral, sobretudo quando analisadas as antigas colônias. Por outro 
lado a crescente importância do transporte e comércio exterior por via marítima vem a acentuar a importância econômica desses ambientes. Fora os aspectos socioeconômicos, é essencial ressaltar sua relevância ambiental, com a presença de ecossistemas e ambientes de equilíbrio sensível como manguezais, estuários e lagunas que atuam como berço para reprodução e alimentação, garantindo equilíbrio da fauna. (GRUBER; BARBOZA; NICOLODI, 2003; MMA \& MPO, 2004; MMA, 2006).

Por todo seu papel socioeconômico, esses ambientes estão sobre constante pressão, seja industrial, urbana, demográfica, ou da crescente atividade do turismo, que vem se expandindo internacionalmente, tendo os espaços litorâneos como um dos principais focos. Sobre o turismo, o litoral apresenta diversidade de opções de atividades de recreação e lazer, propiciando a expansão internacional de práticas de veraneio e segunda residência. Todo esse contexto gera conflitos e antagonismos que requerem um gerenciamento integrado para efetivação de um plano de desenvolvimento mais sustentável. (MMA \& MPO, 2004; MMA, 2006).

A emergência da discussão da problemática ambiental teve como marcos principais a Conferencia de Estocolmo, em 1972, e o "Relatório de Brundtland", onde o conceito de desenvolvimento sustentável foi definido a partir do o tripé básico de economia, sociedade e meio ambiente. Posteriormente, a Agenda 21 trouxe metodologias e propostas de implantação em nível nacional, estadual e municipal. Nesse contexto a criação de espaços protegidos tem papel fundamental e, ao mesmo tempo, objetivos diversos, pressupondo preservação, conservação e uso sustentável dos recursos.

O presente trabalho tem como foco a discussão sobre gestão em áreas de preservação e os conflitos inerentes, utilizando como exemplo prático um estudo de caso em duas Unidades de Conservação no estado do Rio Grande do Sul: Parque Nacional da Lagoa do Peixe (Tavares-Mostardas) e Parque Natural Municipal Tupancy (Arroio do Sal). Dessa forma, em um primeiro momento estará sendo apresentada o arcabouço legal e a questão das áreas de preservação no Brasil, partindo então para a descrição e contextualização dos casos e discussão dos conflitos apresentados. Alem disso, estará sendo discutida a gestão desses espaços tão importantes para preservação do ecossistema costeiro.

\section{2. Áreas de Preservação no Brasil}


Apesar da emergência das questões ambientais na atualidade, o conceito de delimitação de áreas protegidas é antigo, remontando a antiga Pérsia em 5000 a.C. e Mesopotâmia; no ocidente o atual conceito de unidades e áreas de preservação teve seus primórdios na Idade Média. Contudo, como primeira unidade de conservação institucionalizada, é considerado o Parque Nacional de Yellowstone nos Estados Unidos, criado em 1872. Exemplo que foi seguido por diversos países como Canadá (1885), Nova Zelândia (1894), Austrália e África do Sul (1898), entre outros (MEDEIROS, 2006). No Brasil, apesar de as primeiras tentativas de criação de áreas protegidas se remeterem ao período colonial, a primeira unidade de conservação é considerada o Parque Nacional de Itatiaia, em 1937.

Medeiros (2003 apud MEDEIROS, 2006) define áreas protegidas como "espaços territorialmente demarcados cuja principal função é a conservação e/ou a preservação de recursos, naturais e/ou culturais, a elas associados". O autor ainda coloca que a criação de áreas protegidas estabelece limites e dinâmicas de uso e ocupação específicos e por esse motivo pode ser considerada como uma estratégia relevante de controle do território. Milano (1999 apud Faria \& Pires 2007) destaca que as áreas de preservação nasceram para preservação da natureza em sentido amplo, abrangendo hoje temas como: preservação da diversidade biológica, manutenção de serviços ecológicos essenciais, proteção de monumentos naturais e belezas cênicas, promoção de pesquisa científica, educação, recreação, turismo, desenvolvimento regional, entre outros. Nesse contexto, a legislação brasileira tem caráter bastante abrangente e pulverizada na definição de áreas de proteção.

Em sua tese de doutorado, o autor Rodrigo Medeiros (2006) efetua um amplo estudo, descrevendo o histórico e evolução das tipologias e categorias de áreas protegidas no Brasil. Sem aprofundar a discussão sobre o tema - que não é o objetivo desse trabalho - vale destacar os principais marcos legais: capitulo sobre meio ambiente na Constituição Federal; Código Florestal (Lei no 4.771/1965); Regulamento dos Parques Nacionais (Decreto no 84.017/1979); Lei de Crimes Ambientais (Lei Federal no 9.605/1998); Política Nacional de Meio Ambiente (Lei no 6.938/1981); Sistema Nacional de Unidades de Conservação (SNUC, Lei no $9.985 / 2000)$.

O Sistema Nacional de Unidades de Conservação (SNUC) veio para integrar a legislação referente a unidades de conservação e favorecer um processo integrado de gestão. Através dele foram estabelecidas dois grandes grupos de unidades de conservação subdivididos em um total de 12 categorias, conforme abaixo: 
- Unidades de Conservação de Proteção Integral: Estação Ecológica, Reserva Biológica, Parque Nacional, Monumento Natural e Refugio da Vida Silvestre

- Unidades de Conservação de Uso Sustentável: Área de Preservação Ambiental, Área de Relevante Interesse Ecológico, Floresta Nacional, Reserva Extrativista, Reserva de Fauna, Reserva de Desenvolvimento Sustentável, Reserva Particular do Patrimônio Natural

Na mesma linha do SNUC, cabe destacar os sistemas criados nos estados, como o Sistema Estadual de Unidades de Conservação (SEUC) criado no RS em 1992 (regulamentado pelo Decreto no 38.814/98), antes mesmo da criação do SNUC. O SEUC RS tem características bastante semelhantes ao SNUC. Um dos pontos interessantes é que acrescenta a categoria de "Unidade de Conservação de Manejo Provisório", que vem ao encontro do princípio da precaução, se destinando a preservar áreas durante um período suficiente para que sejam executados estudos que comprovem ou não a relevância de torná-las áreas de preservação.

O grande mérito do SNUC foi de reunir e dar um sentido para uma série de categorias que antes estavam dispersas em leis e decretos. Além disso, como já citado, ele estabelece as bases para troca de informações e uma gestão integrada das unidades de conservação do país. Todavia, o SNUC não inclui outras categorias importantes de áreas de preservação instituídas pelo Código Florestal - como as Áreas de Preservação Permanente (APPs) e Reserva Legal. Nesse sentido, Medeiros (2006) ressalta que é necessário ter cuidado para não reduzir o conceito de "áreas protegidas" para "unidades de conservação", que seria apenas uma das categorias da primeira. Outro ponto é que o SNUC atua apenas nas áreas de proteção federais, já que as áreas estaduais e municipais ficam sob regimento dos respectivos sistemas estaduais e municipais; esse acaba por se tornar uma brecha na geração de conflitos e antagonismos no que concerne a nomenclaturas e gestão, além de não integrar as unidades em sentido amplo.

Todavia, a problemática das UCs vem ganhando espaço e esforços estão sendo feitos de modo a uniformizar e tornar mais claros os critérios e regras em sua criação e gestão. Nessa linha, outro ponto a ressaltar foi a criação recente, no ano de 2007, do Instituto Chico Mendes de Conservação da Biodiversidade (ICMBio), que coloca em evidencia a gestão das UCs federais. Apesar disso, não se pode ignorar que a criação do Instituto separa a gestão das UCs do contexto institucional das demais categorias de áreas de preservação, que tendem a ficar carentes de instrumentos de integração e articulação com as ações previstas para as 
Unidades de Conservação. A criação do instituto é muito recente e traz limitação em uma melhor compreensão de seu papel e ações, contudo, a implantação de um cadastro unificado e de programas comuns são uma demonstração clara de que um primeiro passo está sendo dado em direção a uma melhor integração e tratamento das unidades espalhadas pelo país.

\section{Unidades de Conservação no RS: Parque Natural Municipal Tupancy e Parque Nacional da Lagoa do Peixe}

Como foi visto acima, a criação de áreas de preservação é uma antiga estratégia objetivando a preservação ambiental e conservação da biodiversidade, atendendo hoje a diferentes objetivos. O estado RS, particularmente, conta com um importante histórico do movimento ambientalista desde a década de 70 , onde a mobilização culminou com o fechamento da indústria de celulose norueguesa Borregaard (no ano de 1973, devido à poluição causada em Porto Alegre) e impôs importantes critérios de preservação ambiental, segurança e tratamento de efluentes para a instalação do Pólo Petroquímico do Sul (BONES e HASSE, 2002). Nesse sentido, o estado é considerado como precursor no debate de temas e legislações como, por exemplo, a Política Estadual de Recursos Hídricos - na qual a Política Nacional foi muito inspirada - e o próprio SEUC, também anterior ao sistema nacional (CANEPA \& GRASSI, 2002).

Toda essa mobilização em torno da questão ambiental foi determinante na criação e preservação de Unidades de Conservação estudadas no litoral do RS. A partir de agora serão descritos os casos do Parque Municipal Tupancy e do Parque Nacional da Lagoa do Peixe, destacados no mapa abaixo, ressaltando a relevância e características principais de cada UC. 


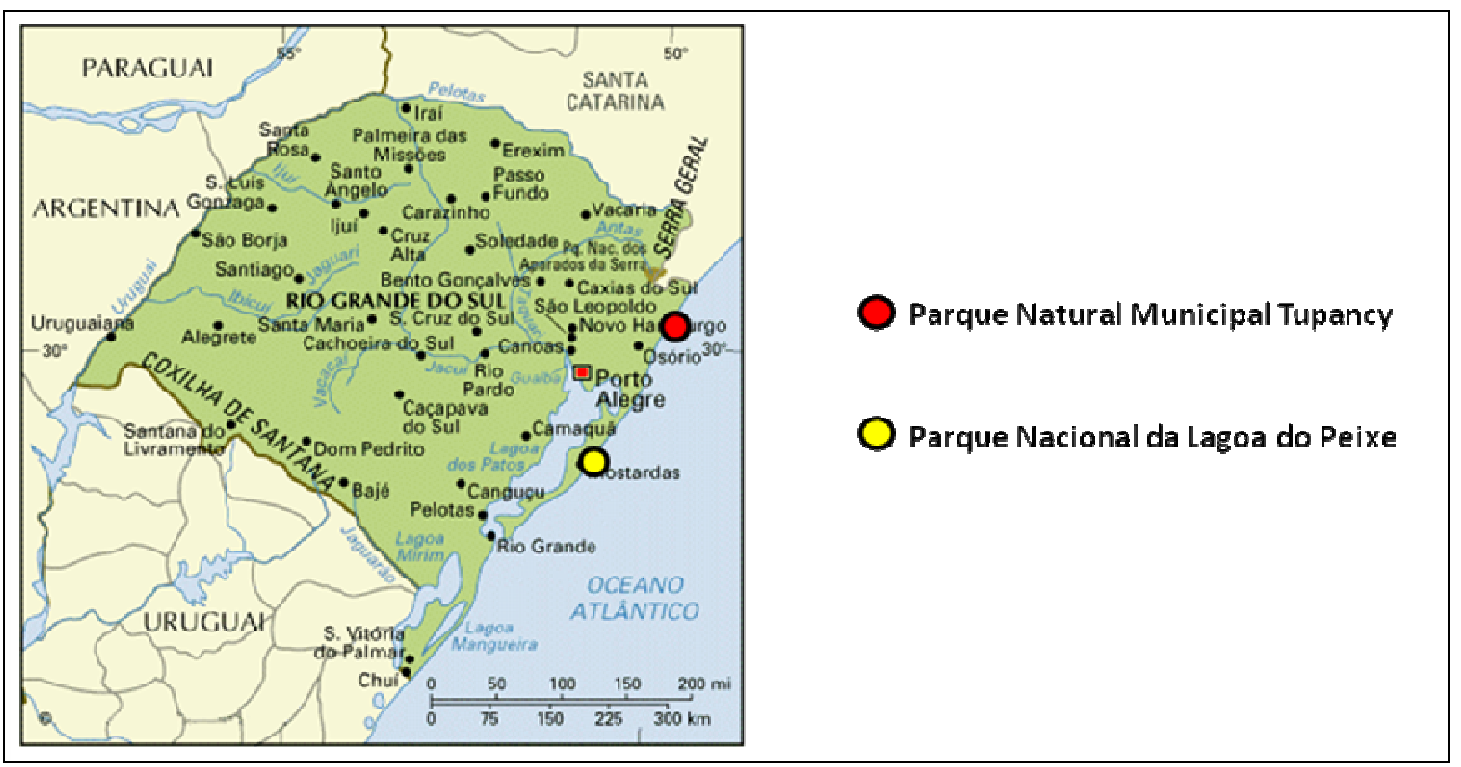

Figura 1: Mapa do RS com destaque para os parques estudados: Parque Natural Municipal Tupancy e Parque Nacional da Lagoa do Peixe.

\subsection{Parque Natural Municipal Tupancy}

O Parque Natural Municipal Tupancy foi criado em 1994 (Lei Municipal 468/94) e está localizado na área urbana do balneário de Rondinha, pertencente ao município de Arroio do Sal, no Litoral Norte do Estado do Rio Grande do Sul, aproximadamente $180 \mathrm{~km}$ de Porto Alegre. Com área de pouco mais de $21 \mathrm{Km}^{2}$ o parque está situado a meio caminho dos três principais pólos de veraneio do Litoral Norte do Rio Grande do Sul (Torres, Capão da Canoa e Tramandaí).

Como pode ser visto nas fotos abaixo, a fisionomia do parque é dominada pela presença de uma duna vegetada, recoberta por mata de restinga, de até $9 \mathrm{~m}$ de altura, e pela presença de três lagoas - a do Banho, a do Remanso ou Rondinha e a do Tupancy ou do criadouro, fronteira ao parque. O Parque também inclui um Criadouro Conservacionista, autorizado pelo Instituto Brasileiro de Meio Ambiente dos Recursos Naturais Renováveis (IBAMA) que abriga espécies nativas e exóticas. 


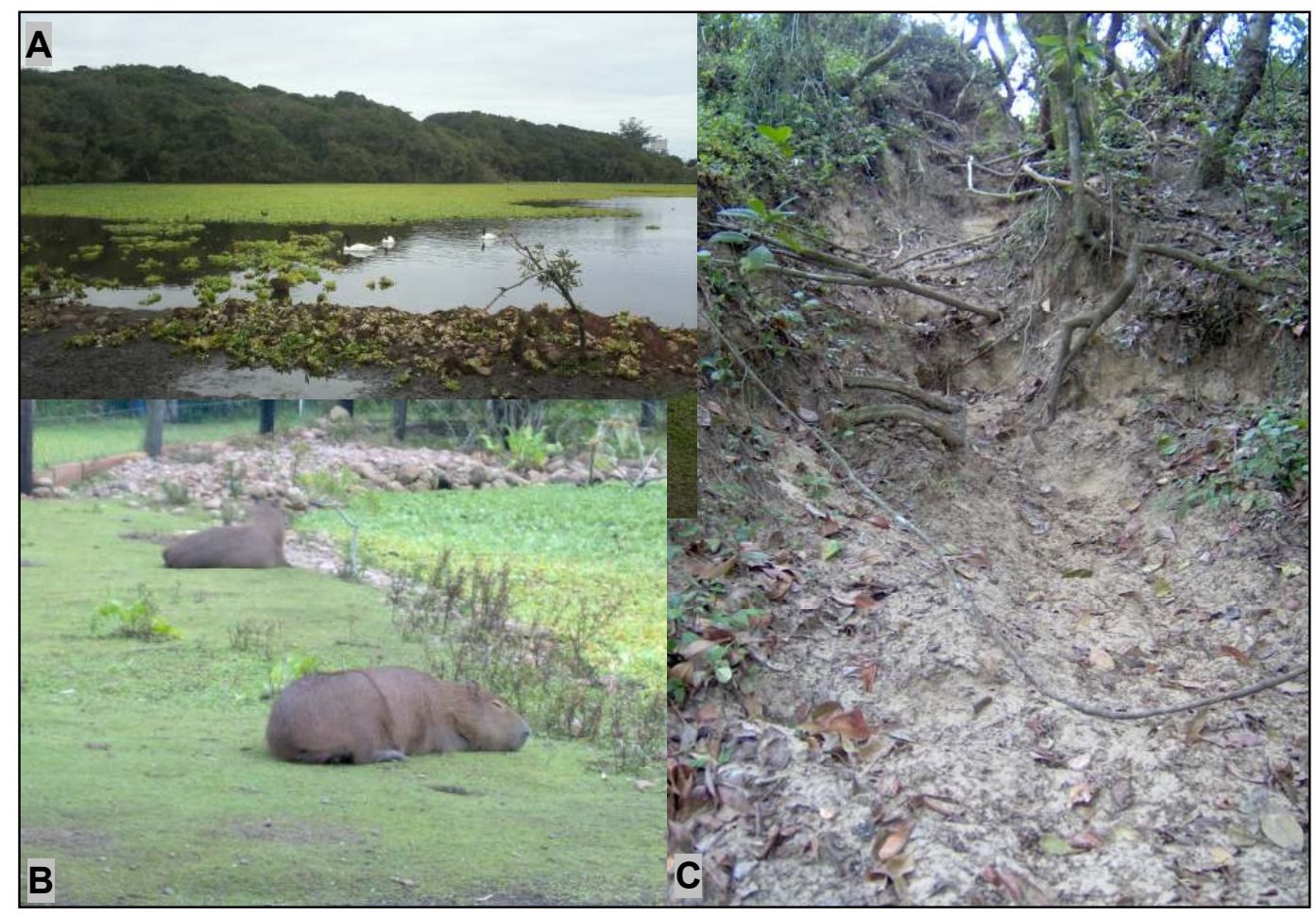

Figura 2: Parque Natural Municipal Tupancy - (A) Visão geral do parque com sua duna vegetada e lagoas; (B) Criadouro Conservacionista; (C) Trilhas na duna, já bastante desgastada pelo excesso de visitação.

Fotos tiradas por Juliane Beatriz Lissner.

Apesar de não possuir ligação direta com o ambiente de praia e de sua área ser considerada pequena para a preservação de espécies ali contidas, o Parque apresenta uma grande variedade de ambientes - como mata, dunas semi-fixas, dunas móveis, campos diferenciados, capões, laguinhos, lagoas, entre outros. Estudos foram feitos no local de modo a apurar e classificar a flora, mas a fauna ainda carece de um maior detalhamento. Outro ponto a destacar é a ocorrência de sambaquis, que são um testemunho da ocupação da planície remontando a pré historia (ARROIO DO SAL, 2002).

A criação do Parque contou com o apoio e reivindicação da comunidade, em uma área fortemente sujeita à pressão imobiliária. Mais recentemente foi criada a AAT, Associação de Amigos do Parque Tupancy, com intuito de participar das decisões e auxiliar no manejo do Parque. Algumas ações de educação ambiental são desenvolvidas, com a visita de pesquisadores e escolas, contudo o potencial de visitação é enorme, chegando a 300 pessoas/dia no ultimo feriado de Páscoa.

Com relação à estrutura, o Parque possui um centro de visitantes, responsável por receber os turistas e dar orientações para a visitação. Hoje, a entrada é gratuita, o que os gestores do Parque justificam pela falta de pessoal para atuar como guia durante a visitação. 
Além disso, a área do parque área não é inteiramente cercada e isolada o que dificulta o controle do acesso de visitantes. Nesse ponto se faz necessária uma ação imediata, pois, o excesso de visitação e circulação nas trilhas está contribuindo para a degradação do espaço, conforme pode ser visto na Figura 1c.

No aspecto gerencial, o Parque possui uma equipe bastante reduzida e gestão ligada a Secretaria Municipal de Agricultura e Desenvolvimento do município. Desde sua criação, é possível perceber uma dificuldade na continuidade da gestão, já que fica a cargo de governos que podem se alternar a cada eleição. A implantação efetiva do plano de manejo desenvolvido para o parque e adoção de ações de longo prazo são importantes para garantir a continuidade no processo de gestão.

\subsection{Parque Nacional da Lagoa do Peixe}

O Parque Nacional da Lagoa do Peixe foi criado em 1986 (Decreto $n^{\circ} 93.546$ de 06.11.1986) e está localizado no litoral sul do RS, com a maior parte de sua área município de Tavares (80\%), abrangendo também Mostardas (17\%) e São José do Norte (3\%). A unidade possui área de $332 \mathrm{Km}^{2}$ e está a cerca de $200 \mathrm{~km}$ de Porto Alegre.

O objetivo central do Parque é a proteção de ecossistemas litorâneos e das espécies de aves migratórias, que dependem da unidade. Aliado a isso, somam-se objetivos científicos, culturais e recreativos. O nome do Parque se deve a importância da Lagoa do Peixe para a região, como abrigo para populações de aves migratórias do hemisfério norte e sul. $\mathrm{Na}$ verdade, a Lagoa é uma laguna, pois possui ligação, através de um canal natural, a maior parte do ano. Essa ligação é responsável pelo sensível equilíbrio das características físioquímicas da água, que propicia vida a peixes, essenciais na alimentação das aves.

A paisagem do parque é completada por dunas, banhados e matas de restinga. Os ecossistemas dessa estreita faixa de terra entre a laguna dos Patos e o Oceano Atlântico tem características tão particulares que a região foi considerada pela UNESCO como Reserva da Biosfera. 


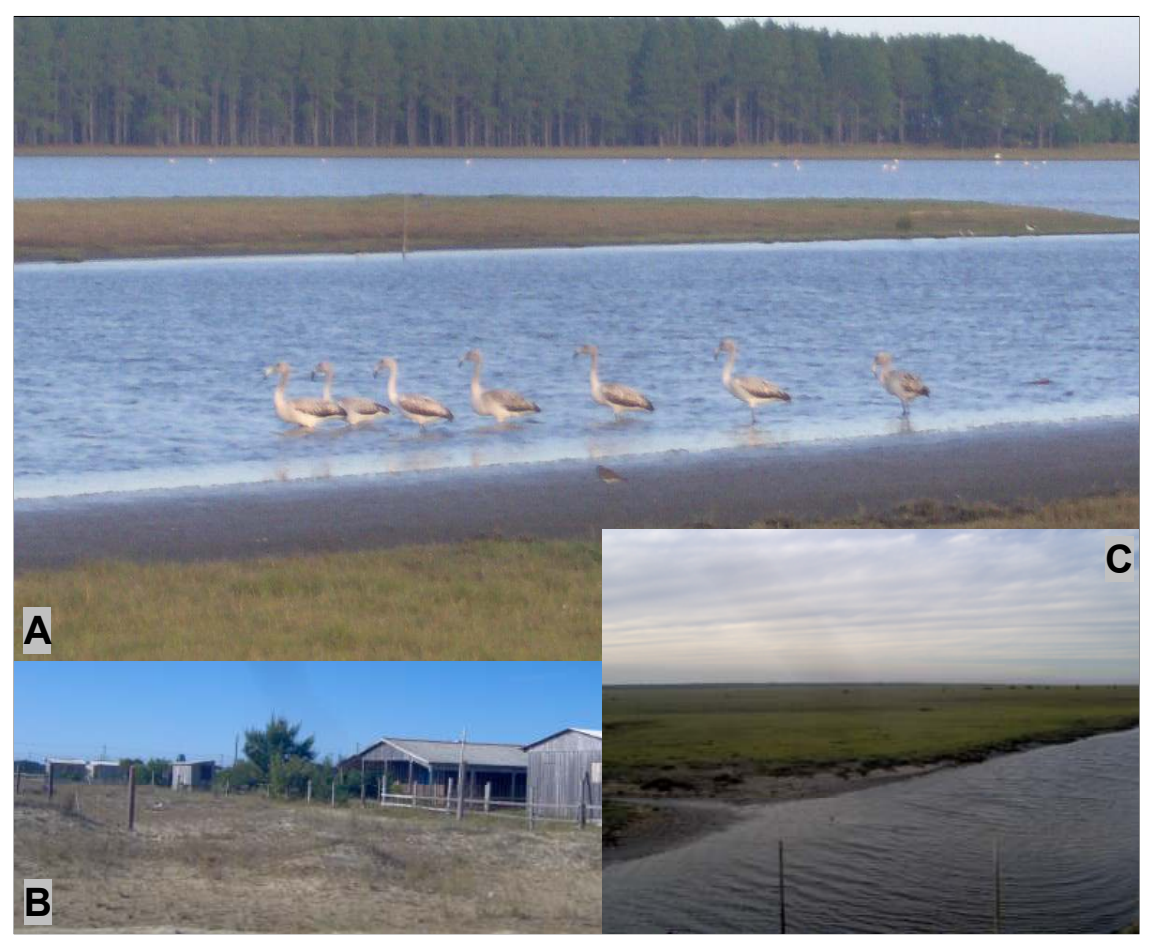

Figura 3: Parque Nacional da Lagoa do Peixe - (A) Lagoa do Peixe com pinus ao fundo; (B) Residência na área do Parque; (C) Lagoa com área de agricultura ao fundo.

Fotos tiradas por Sandro Sidnei Vargas de Cristo.

Um ponto que se sobressai na paisagem é a presença de vegetação exótica, o pinus. Além de modificar a região, existem indícios, a partir de relatos de pescadores, de que o pinus esteja contribuindo diretamente para a diminuição da disponibilidade de água na laguna. Tais conflitos levaram o Ministério Público Federal a mover ação contra o Parque, em 2006, com enfoque na retirada do pinus. O Parque "perdeu" o processo e houve a solicitação judicial para retirada das árvores. Tal fato corroborou para uma reestruturação na gestão do Parque e revisão de outros pontos no processo como a ocupação e regularização fundiária.

A sede administrativa do Parque é na praça central da cidade de Mostardas, sendo que o Parque não possui centro para acolhimento de visitantes em seu perímetro. A estrutura de gestão é composta por um cargo de direção, na natureza de cargo de confiança, 2 servidores concursados do IBAMA/ICMBio, mais servidores terceirizados, trabalhando com apoio administrativo e de campo. Com relação à visitação, o Parque é um importante atrativo turístico para a região, todavia não se tem dados sobre quantidade e perfil dos visitantes devido ao Parque ser um espaço aberto, sem limitação para entrada.

Com relação à comunidade local, a criação do Parque trouxe conflito, sobretudo para a população rural e pescadores. O censo de 1996 aponta que os limites do Parque atingem parcialmente 331 propriedades, de diversos tamanhos, destinadas a agricultura e pecuária, 
cujas terras mais férteis se encontram no interior na UC (parte inferior da Barreira III, que sofre inundação nas cheias da laguna) (FURG, 2009). A regularização fundiária ainda está pendente e coexiste entre a comunidade local o temor pela desapropriação e a vontade de permanecer nas terras que muitas vezes estão de posse da família a varias gerações. Com relação aos pescadores artesanais, o controle exigido pelo Parque implica em cadastro e fiscalização; hoje aproximadamente 170 pescadores estão cadastrados, com autorização para realizar pesca na área do Parque.

Outro ponto de conflito é a zona de entorno que, pela legislação nacional, o Parque possui ingerência em uma área de $10 \mathrm{Km}$ a partir de seus limites, o que pode causar um conflito com a população local. Além disso, existem as construções de habitações de veraneio na área do Parque, em Terrenos de Marinha, permitidas pelas prefeituras sem a autorização da União, que criam uma situação sem responsáveis diretos e prejudicam a preservação da região. Todavia, cabe ser ressaltada a ação da população local no sentido de conviver e contribuir para preservação da área: relatos de moradores antigos dão conta de que a população teve historicamente um papel importante para que a Lagoa permanecesse preservada por tanto tempo.

Por sua importância e riqueza, diversos estudos científicos vêm sendo efetuados no Parque, todavia, não há um sistema integrando tais resultados. Além disso, muitas vezes os estudos não apontam para decisões práticas de gestão. O Parque não possui estrutura própria para desenvolver estudos; são vislumbrados convênios com universidades para suprir tal demanda.

Assim como no Parque Tupancy, a UC da Lagoa do Peixe também sofre com uma equipe reduzida para as dimensões do parque. Além disso, somam-se problemas com falta de estabilidade na direção e carência no repasse de recursos para a efetiva implantação de um

processo de gestão de longo prazo. A implantação do plano de manejo na unidade e efetivação dos convênios com universidades e instituições de pesquisa deve contribuir decisivamente para a geração de um banco de informações que permitam o planejamento no longo prazo.

\section{Gestão e conflitos em áreas de preservação}

A partir dos casos analisados acima, é possível verificar a enorme gama de desafios enfrentados na gestão desses espaços tão importantes. $\mathrm{O}$ cenário básico de atuação na gestão 
desses espaços, invariavelmente, é composto por ambientes sensíveis e de relevância, sujeitos a pressões em diversos níveis, que podem gerar conflitos. Nesse sentido, a atuação da gestão dessas áreas passa pela conciliação de interesses e posicionamentos para atender ao objetivo principal, que é a preservação.

\subsection{Pressões e conflitos}

Pela própria característica inerente à composição e manutenção das UCs, essas áreas tendem a sofrer pressões e conflitos diversos. A seguir, serão listados e discutidos brevemente os principais pontos encontrados nos casos estudados.

\subsubsection{Agropecuária}

Conflitos envolvendo áreas de preservação e a atividade de agropecuária são freqüentes e vão além do escopo da problemática das UCs, já que a legislação impõe restrições de utilização do espaço (áreas de preservação permanente e reserva legal, por exemplo) que se chocam com os interesses dos proprietários.

Nos casos estudados, o conflito é presente na UC da Lagoa do Peixe e agravado pela não regularização fundiária. Como visto anteriormente, a criação do Parque implicou na "desapropriação" das terras mais férteis, para a área de preservação, o que impacta diretamente os produtores. Outro ponto é com relação a pratica de pecuária: é possível ver os animais, oriundos de pratica de pecuária extensiva, dentro dos limites do Parque.

\subsubsection{Pescadores}

Questão presente na Lagoa do Peixe, onde é permitida a pesca do camarão-rosa para os pescadores cadastrados, cerca de 170. A avaliação dos estoques pesqueiros é um tema bastante delicado, devido à própria natureza dos cardumes, que não permanecem em pontos fixos, por isso, programas de preservação devem ser cuidadosos no estabelecimento de limites e regras. Na verdade, o fato é que, pela natureza de Parque Nacional, não deveria ser permitida a pesca em seus limites. Contudo, por se tratarem de pescadores artesanais, que já se utilizavam dessa pratica por um tempo anterior a criação da reserva, a pesca é permitida com algumas restrições - que implicam cadastro e fiscalização. 


\subsubsection{Vegetação exótica}

A questão da implantação de florestamento com pinus esta disseminada por varias regiões no estado, não sendo um privilégio da zona costeira. Da mesma forma, diversos estudos vêm sendo efetuados de modo a acompanhar os impactos dessa pratica.

No caso da Lagoa do Peixe, o florestamento com vegetação exótica pode estar contribuindo diretamente para a diminuição do volume de água da laguna. Apesar de a retirada da vegetação estar determinada pela justiça, deve ser feita com muita cautela, para não interferir no equilíbrio do Parque.

\subsubsection{Comunidade local}

A convivência da comunidade local com as Unidades de Conservação são sempre questões delicadas, que merecem atenção e trabalho continuo de educação ambiental. Em ambos os casos, vemos que a comunidade teve um papel importante na preservação das áreas: no Parque Tupancy a atuação foi decisiva para a criação da reserva e na Lagoa do Peixe, para a conservação da região, mesmo antes da instituição do Parque.

O fato é que qualquer plano de manejo e gestão, para ser efetivamente aplicado, passa pela adequada sensibilização da comunidade local e sua colaboração no processo. Um caso que pode ser considerado de sucesso, nesse sentido, é o Projeto Tamar, que teve como cerne a educação das comunidades, mostrando a importância da preservação das tartarugas marinhas e gerando alternativa de renda para essas populações.

\subsubsection{Turismo}

Nos casos apurados, o turismo pode ser considerado como fator de pressão ambiental e, ao mesmo tempo, de atração de visitantes, gerando oportunidade para a comunidade local. $\mathrm{Na}$ região da Lagoa do Peixe, o Parque é a grande atração da região e o município de Mostardas vem trabalhando com divulgação e realização de festas anuais, que aproveitam a o período de mais intensa migração das aves para atrair visitantes. Já Arroio do Sal vem adotando fortemente a estratégia de preservação ambiental, o que acaba por diferenciar sua paisagem das praias vizinhas - fortemente urbanizadas. Nesse contexto, o Parque Tupancy atua como um atrativo adicional, corroborando a estratégia adotada. Do mesmo modo, o 
turismo, acompanhado do fenômeno da segunda residência, é um importante indutor no aumento da pressão imobiliária, vista a seguir.

Todavia, não se tem um controle efetivo do numero total de visitantes e seu perfil. Esse tipo de estatística é importante para conhecer os freqüentadores e melhor direcionar ações de educação ambiental. Além disso, esse conhecimento traz oportunidade de parcerias e venda de espaços publicitários, o que pode ser importante fonte de receita alternativa às UCs.

\subsubsection{Pressão imobiliária}

O aumento da pressão imobiliária na zona costeira está fortemente relacionado à atividade de turismo e mudou radicalmente a paisagem do litoral gaucho nos últimos 20 anos, principalmente com a verticalização da orla e criação de condomínios de luxo.

Nos casos do Parque Tupancy, a pressão pela atividade turística é bastante visível e os limites do Parque estão povoados por moradias de veraneio. Antes da criação da reserva, a área seria destinada para loteamento e venda, o que não ocorreu pela pressão popular e doação da área para composição da reserva. Já na Lagoa do Peixe, a urbanização começa a se aproximar do Parque, em alguns casos, invadindo seus limites. Na maior parte das vezes, as construções são autorizadas pelas prefeituras, sem comunicação/acordo com os órgãos ambientais e outras instancias. Assim, a população instalada reivindica infra-estrutura básica no local, que acaba por legitimar a ocupação dessas áreas e colocar em risco sua preservação.

\subsubsection{Legislação x competências}

Talvez, seja este um dos principais conflitos da gestão da zona costeira na atualidade. O conflito de legislação e competências de fiscalização se manifesta tanto na demarcação das UCs quanto na gestão dos municípios.

Como vimos anteriormente, a legislação nacional é bastante fragmentada; o SNUC e a criação do ICMBio vieram para unificar a gestão das UCs federais, mas possuem duas lacunas bastante importantes: (a) não incorporam as UCs estaduais e municipais (no caso estudado, o Parque Nacional da Lagoa do Peixe é de competência federal/ICMBio e o Parque Natural Municipal Tupancy é do município, ligado também à Secretaria Estadual do Meio Ambiente (SEMA); (b) separa as UCs das demais áreas de preservação.

Dessa forma, é possível verificar a falta de clareza com relação às competências pela fiscalização e tomada de decisão, seja nas próprias UCs, seja em seu entorno. Nesse ultimo, a 
área dos Parques se confunde com áreas de competência federal (terrenos de marinha), áreas de preservação, de um modo amplo, e com a competência municipal de estrutura e licenciamento.

\subsection{Gestão em Unidades de Conservação}

Todas as abordagens relativas ao conceito de gestão, a começar pelas idéias clássicas de Henri Fayol, remetem a problemática da definição de objetivos - quantificados em metas, num espaço de tempo - e ao ordenamento dos recursos e esforços para alcançá-los. Dessa forma, são implícitas as famosas fases de planejar, organizar, comandar, coordenar e controlar, já definidas por esse famoso autor antes de 1900. Cada uma dessas fases tem suas características próprias e podem ser aplicadas a qualquer tipo de projeto ou organização.

Contudo, quando vamos tratar das questões ambientais, nos deparamos com temas amplos e complexos, que envolvem conhecimento técnico em áreas tão diversas como biologia, física, química, geografia, geologia, entre outros, aliado a um amplo conhecimento e capacidade de analise e síntese da legislação vigente. Dessa forma, sistematizar todo esse conhecimento e converte-lo em um sistema de gestão adequado a realidade das UCs é uma tarefa complexa, que requer o uso integrado de ferramentas.

Uma tendência que pode ser identificada, é de uma abordagem focada em um nível técnico, no sentido de definir o uso e manejo da área. Nesse sentido, um essencial instrumento para orientar a ação deve ser o plano de manejo, que atue dando subsidio aos gestores no planejamento e tomada de decisão. Scardua (2007) explora a forma de construção dos planos em nosso país. De uma forma geral, são documentos amplos, que tratam de aspectos naturais e humanos envolvendo a área em questão, contudo, segundo o autor, são poucas as UCs que possuem um plano e, dentre estas, a maioria não consegue partir para a implementação.

Fatos como esse mostram que a gestão de UCs é muito mais complexa que a tomada de decisões técnicas, exigindo estruturação para efetivar as ações. Recentemente, o Ministério do Meio Ambiente fez o lançamento do programa "Estratégia Nacional de Comunicação e Educação Ambiental no SNUC" (ENCEA) com objetivo principal de sistematizar conceitos e orientar ações. O ENCEA pressupõe que a gestão de Unidades de Conservação é composta de processos diversos nos quais, além das atividades próprias de administração da UC, estão englobados: (a) consolidação territorial, (b) proteção, (c) fiscalização, (d) manejo da biodiversidade e dos recursos naturais, (e) uso público e, (f) pesquisa e monitoramento. O 
ENCEA é uma ferramenta bastante interessante, que aborda desde o diagnostico para a implementação de UCs, treinamentos, referencial político e legal, orientação para ações de educação ambiental, além de fundamentos de gestão propriamente ditos. Como sua publicação data de maio/2009, ainda não é possível avaliar sua implantação e impactos.

Na mesma linha, trabalho de Debetir \& Orth (2007) propõe um interessante sistema de gestão para UCs, com o cuidado de separar variáveis estratégicas e operacionais e gestão de decisões técnicas. No trabalho, em um primeiro momento, é proposta a definição de princípios e diretrizes, os primeiros para garantir a coerência na formulação da estratégia e o segundo dando linhas gerais de orientação. A partir daí é delineada a atuação de três grupos gestores - (1) decisor, (2) executor, e (3) colaborador - e quatro sistemas de suporte, abordando os aspectos organizacional, de informação, financeiro e o suporte cientifico. Em sua metodologia, as autoras conseguem permear de uma maneira ampla as questões envolvendo a gestão de UCs, sistematizando em uma proposta viável, que enfatiza a colaboração da comunidade nas decisões e a necessidade contínua de monitoramento da área através de geração e coordenação de informações e estudos.

Um dos pontos destacados nos casos estudados é a dificuldade na captação de recursos para a gestão do parque. A grande questão é que o trabalho de preservação não "termina" com a declaração de uma área de preservação, ele apenas “se inicia”. Uma vez UC, são necessários investimentos contínuos para manutenção do espaço, que envolve contratação de pessoal, ações de educação, desenvolvimento de estudos, entre outros. Em ambos os casos estudados, os recursos provem majoritariamente do poder público. Como alternativas de financiamento Debetir \& Orth (2007) citam diversas opções, tais como: Fundo Nacional do Meio Ambiente (FNMA), Fundo Estadual/Municipal do Meio Ambiente, Lei Rouanet (Lei no 8.313/91), Convenio ou Termo de Cooperação Técnica, Termo de Cessão de Uso de Espaço Publicitário, Termo de Ajustamento de Conduta. Pode ser acrescentado a essa lista os fundos internacionais e a cobrança pela visitação.

Sobre esse ultimo tópico, a visitação, é essencial que em qualquer processo de gestão ela seja incentivada, porém com o devido planejamento. O próprio ENCEA ressalta a necessidade do "uso público" da área, que são compreendidos como atividades de visitação, recreação e turismo. Todavia, o programa ressalta que deve ser primeiramente efetuado o plano de manejo, compondo as orientações técnicas e identificando o potencial de carga da área, para então o conselho gestor definir a melhor forma de execução, respeitando os limites para preservação da área. 
Por fim, um ponto ressaltado nos casos estudados e nos sistemas de gestão propostos é a necessidade contínua de gestão da informação, monitoramento e pesquisa científica. É certo que, na maior parte das vezes, as UCs isoladas não possuem corpo técnico ou estrutura para, sozinhas, desempenharem tal papel. Nesse ponto, as parcerias e convênios de cooperação técnica aparecem como alternativas viáveis e de interesse de ambas as partes.

\section{Considerações finais}

Ao longo do trabalho, pode ser visto um panorama da questão das Unidades de Conservação, percorrendo questões institucionais, um estudo de casos práticos e evidenciando a problemática da gestão dessas áreas. Pode ser visto que uma gestão efetiva dentro de um cenário institucional confuso, multiplicidade de partes interessadas e conflitos latentes é certamente um desafio de grande envergadura para as UCs. Para fazer frente a ele, muitas vezes, o que se vê é um quadro institucional pouco estável, acompanhado de equipes pequenas, com poucos recursos, sem condições de garantir uma verdadeira continuidade nas ações. Dessa forma cresce a necessidade de profissionalização da gestão e organização de um sistema que de suporte para a tomada de decisões.

Diante de uma legislação confusa e fragmentada, cresce a necessidade de atenção e estudo para uma correta compreensão e aplicação. Nesse sentido a criação do SNUC e ICMBio vem como tentativas de unificação importantes - mesmo levando em conta suas limitações estruturais. Um caminho ainda a percorrer é o da integração de UCs estaduais e municipais e um melhor dialogo e manejo integrado com outras categorias.

É essencial ressaltar a importância do envolvimento e motivação da população para a conservação das áreas, que foi determinante em ambos os casos estudados. O trabalho de educação deve ser continuo para que a criação do parque não se torne uma barreira aos habitantes locais. Aliado a isso, deve ser evidenciado o processo de manutenção contínua, que envolve monitoramento das áreas e desenvolvimento de pesquisas científicas.

De um modo geral, é importante compreender que a profissionalização e organização da gestão vai além do plano de manejo, exigindo atuação competente dos órgãos gestores na busca de recursos e gestão efetiva que atinja os resultados pretendidos. Afinal, essas áreas tão importantes devem se configurar em áreas efetivamente sustentáveis para garantir a sua função primordial no desenvolvimento sustentável da zona costeira. 


\section{Referências bibliográficas}

ARROIO DO SAL. Plano de Manejo Parque Natural Municipal Tupancy. Arroio do Sal, 2002.

BONES, Elmar; HASSE, Geraldo. Pioneiros da ecologia: breve história do movimento ambientalista no Rio Grande do Sul. Porto Alegre: Já Editores, 2002.

CÁNEPA, E.M. \& GRASSI, L.A.T. A lei das águas do Rio Grande do Sul: no caminho do desenvolvimento sustentável. Ciência \& Ambiente, 21: 132-152, Santa Maria: UFSM, 2002.

DEBETIR, E. \& ORTH, D. Estratégias de gestão para unidades de conservação. In: ORTH, D. \& DEBETIR, E. [org.] Unidades de Conservação: gestão e conflitos. Florianópolis: Editora Insular, 2007. p. 43-66

FAYOL, H. Administração industrial e geral. São Paulo: Atlas, 1989. 10 ed.

FARIA, H.H. de \& PIRES, A.S. Atualidade na gestão de unidades de conservação. In: ORTH, D. \& DEBETIR, E. [org.] Unidades de Conservação: gestão e conflitos. Florianópolis: Editora Insular, 2007. p. 11-42

FURG. Parque Nacional da Lagoa do Peixe. Disponível em $<$ http://www.furg.br/furg/projet/pnlpeixe/>. Acesso em 28 jun. 2009.

GRUBER, N.L.S; BARBOZA, E.G; NICOLODI, J.L. Geografia dos sistemas costeiros e oceanográficos: subsídios para gestão integrada da zona costeira. GRAVEL, no 1, 2003, p. 81-89.

IBAMA. Parque Nacional da Lagoa do Peixe. Disponível em $<$ http://www.ibama.gov.br/siucweb/mostraUc.php?seqUc=66>. Acesso em 2 jul. 2009.

ICMBio. Informações Gerais das Unidades de Conservação Federais. Disponível em $<$ http://www.icmbio.gov.br/>. Acesso em 15 jul. 2009.

MEDEIROS, R. Evolução das tipologias e categorias de áreas protegidas no Brasil. Ambiente \& Sociedade. vol IX, no 1, 2006, p. 41-64. 
MEDEIROS, R.; IRVING, M.; GARAY, I. A Proteção da Natureza no Brasil: evolução e conflitos de um modelo em construção. RDE. Revista de Desenvolvimento Econômico, $\mathrm{n}^{\circ} \mathrm{V}$, ano VI, no. 9, 2004, p. 83-93.

MMA. Projeto Orla: fundamentos para gestão integrada. Brasília: MMA, 2006.

MMA. Estratégia nacional de comunicação e educação ambiental no SNUC. Brasília: MMA, 2009.

MMA \& MPO. Projeto Orla: subsídios para um projeto de gestão. Brasília: MMA e MPO, 2004.

SCARDUA, F.P. Práticas brasileiras na elaboração de planos de manejo. In: ORTH, D. \& DEBETIR, E. [org.] Unidades de Conservação: gestão e conflitos. Florianópolis: Editora Insular, 2007. p. 89-110.

SEMA. Unidades de conservação. Disponível em

$<$ http://www.sema.rs.gov.br/sema/html/bio.htm>. Acesso em 20. Jun. 2009. 